\title{
Spider Silk Biomimetics Programs to Inform the Development of New Wearable Technologies
}

\author{
Sean J. Blamires ${ }^{1 *}$, Patrick T. Spicer ${ }^{2}$ and Patricia J. Flanagan ${ }^{3}$ \\ ${ }^{1}$ The Spider Silk Research Lab, Evolution \& Ecology Research Centre, School of Biological, Earth \& Environmental Sciences, \\ The University of New South Wales, Sydney, NSW, Australia, ${ }^{2}$ Complex Fluids Group, School of Chemical Engineering, \\ The University of New South Wales, Sydney, NSW, Australia, ${ }^{3}$ Faculty of Art and Design, The University of New South Wales, \\ Sydney, NSW, Australia
}

\section{OPEN ACCESS}

Edited by:

Nicola Maria Pugno, University of Trento, Italy

Reviewed by:

Johnny De Nardi Martins, Federal University of Santa

Catarina, Brazil

Philippe Boisse,

Institut National des Sciences

Appliquées de Lyon (INSA

Lyon), France

*Correspondence:

Sean J. Blamires

sean.blamires@unsw.edu.au

Specialty section:

This article was submitted to

Polymeric and Composite Materials,

a section of the journal

Frontiers in Materials

Received: 17 October 2019 Accepted: 28 January 2020

Published: 18 February 2020

Citation:

Blamires SJ, Spicer PT and Flanagan PJ (2020) Spider Silk

Biomimetics Programs to Inform the Development of New Wearable Technologies. Front. Mater. 7:29. doi: 10.3389/fmats.2020.00029
Wearable fabrics are predominantly produced from synthetic polymer fibers derived from petrochemicals. These have negative effects on the natural environment as a consequence of the manufacturing process, insurmountable waste production, and persistence of the fibers in ecosystems. With the use of wearables worldwide set to increase exponentially, more environmentally friendly fibers are sought. Natural fibers such as spider silk are produced using proteins in a water solvent, yet they have many superior qualities to synthetic fibers. Moreover, spiders can tune their silk properties as their ecological circumstances demand it. Research focused on the biomimetic potential of spider silks with an eye on the development of smart wearable fibers is accordingly a potentially lucrative area of research. There are nonetheless major challenges associated, including recovering the original mechanical performance within the fibers developed, scaling up production, keeping the production costs of the silk building blocks to a minimum, elucidating, and understanding the different silk genome sequences, and creating precision artificial spinning processes. We outline herein a template for a working framework for a spider silk biomimetics program that can inform designers and biological researchers alike. It suggests that an objective-focused research program utilizing a cross-disciplinary toolbox of top-down and bottom-up techniques is required. We close by providing some speculative examples stemming from current activities in our laboratories.

Keywords: biomimetics, spider silk, environmentally sustainable manufacturing, structure-function properties, wearable technology

The way that wearable materials are currently designed and produced is not sustainable (Carr and Gibson, 2016). Given the inevitable rise in global population and the associated expansion in wearables consumption over the next 30-50 years (Franklin, 2018), there is an urgent need to reduce the environmental impact associated with the production of wearable fabrics across product life cycles (Le Quéré et al., 2009; Myers, 2014).

Man-made and synthetic materials such as rayon and polyester have predominated wearable designs since the 1950's (Franklin, 2018). These materials are primarily derived from the polymerization of petrochemical monomers, which involves high temperatures and treatments that use noxious solvents, before spinning them through syringes, valves, microspinnerets, electrospinners, or 3D printing devices (Damiati et al., 2018). Post-spinning treatments with 
additional noxious chemicals is often required to dry and fix the polymers into solid fibers. The primary advantage of developing fibers this way is that vast quantities can be produced for a wide variety of purposes at a relatively low cost (Wu et al., 2017). The problem nevertheless with creating materials this way is that it is extremely environmentally harmful due to the handling and disposal of the solvents used during spinning and fixing, and the energy input required to treat and fix the materials. The post-production environmental damage is, however, more striking. A $5 \mathrm{~kg}$ wash of polyester fabrics for instance releases over 6,000,000 microfibers that remain in the environment and can act as reservoirs for organic pollutants (De Falco et al., 2018). Additionally, the mass production of materials for fastfashion results in textile wastes contributing to $5 \%$ of the world's landfill (Nguyen-Robertson and Byrne, 2019). Furthermore, the substantial overstock of fabrics gets either burnt or contributes further to landfill. Once in landfill or drainage systems the fibers seep into soil and ocean ecosystems where they persist for 10$1,000 \mathrm{~s}$ of years (Szostak-Kotowa, 2004). Even more disturbing, the fibers can become rapidly incorporated into ecological and human food webs (Browne et al., 2008).

There is evidently a growing market for sustainable, reclaimed, organic, textiles and a renewed interest in merging traditional crafting skills with new technologies (Quinn, 2010). Natural materials such as silks, elastin, resilin, byssus, and wool are examples of fibers derived from natural proteins, which are synthesized and secreted by animals using water as the solvent (Waite, 1992; Abascal and Regan, 2018). Although they are made from biological macromolecules, such as polypeptides, polysaccharides, and lipids, and treated with water and air, many natural materials have superior properties on multiple measures of performance than synthetic material (Liu and Zhang, 2011). For instance, spider dragline silk (Liu and Zhang, 2011; Blamires et al., 2017) has greater strength, elasticity, and toughness than most natural or synthetic materials (Table 1). Particularly important is the fact that silks are easily degraded by natural enzymes after relatively short periods of time (Gellynck et al., 2008), removing the persistent accumulation effect associated with synthetic fibers. Accordingly, if we could replicate the production processes of these natural fibers we might be able to circumvent much of the environmental damage associated with using synthetic polymers for wearable technologies (Eadie and Ghosh, 2011; Lapidot et al., 2012).

Despite great urgency being placed on the development of new environmentally benign materials, there have been few examples of the successful development of processes producing materials that mimic silks or other animal products (Wolff et al., 2017). Biomimetics, or the transfer of functional principles from living systems to engineering applications offer one way forward (Sanchez et al., 2005; Pawlyn, 2011; Wegst et al., 2015; Wolff et al., 2017).

Traditionally an engineer, or designer, might have sought a solution to a particular design problem by examining similar mechanisms in living systems. Indeed, there are examples of successful biomimetic technological processes that have this kind of top-down approach. These include the development of superhydrophobic surfaces based on the lotus leaf, and the

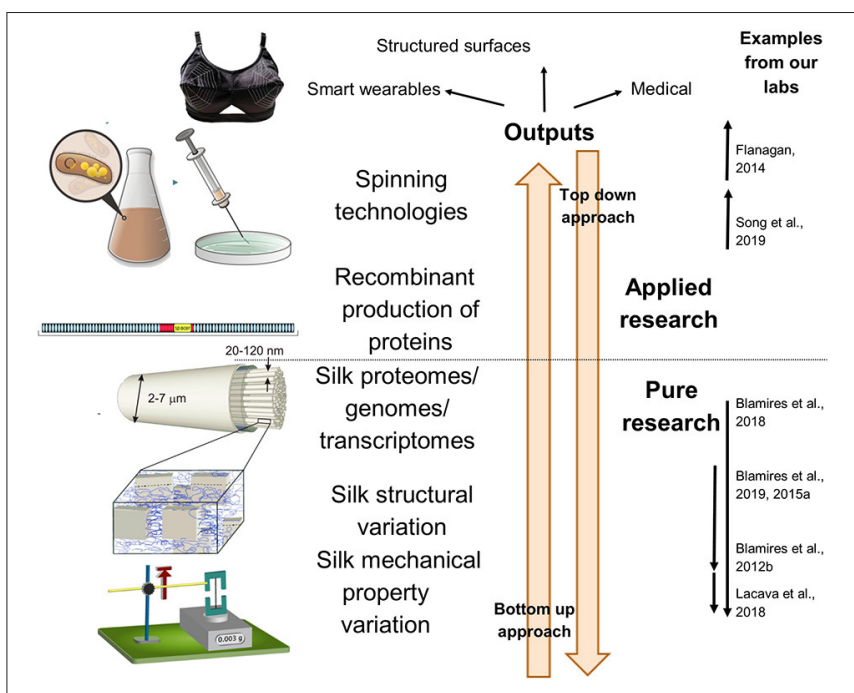

FIGURE 1 | An overview of the components and working principals of a complete and multidiscipline biomimetics research program aiming to develop wearable technologies, and other marketable materials, based on the structures, and functions of spider silks. It shows how combining pure and applied research can produce outcomes and the distinctions between taking top down (starting at the application to search for a natural function) and bottom up (i.e., observing a function and then ask questions of its application) approaches. Examples of research from our laboratories is given for each level.

"shark skin" drag-resistant swim suit (Hwang et al., 2015). Researchers in the biological and other sciences, nonetheless, generally solve problems using bottom-up approaches, i.e., they start by observing a function and then ask questions of its significance and application (Speck et al., 2017; Figure 1). These seemingly disparate approaches can lead to disconnections between the endeavors of designers and scientific researchers and may obstruct our capacity to incorporate advanced technologies into new materials.

How might research programs grounded in pure science ever inform the development of new wearables? Flanagan (2014) advocates a "toolbox" methodology (i.e., adopting tools from different disciplines) to form successful interdisciplinary research programs. In addition to using such a methodology the various participants must clearly define their objectives and working principals if quality biomimetic outcomes are to be realized (Myers, 2014; Wolff et al., 2017). Nevertheless, it is exceptionally difficult for biologists, engineers and designers from their various sub-disciplines to speak with each other using a common vernacular, so the capacity for researchers across the arts and sciences to communicate effectively with those from outside their respective discipline seems ill-fated at the outset. To circumvent this we establish herein a template for a spider silk biomimetics program that informs designs while remaining grounded within a biological research paradigm (see Figure 1).

The first objective of any biomimetics research program is to identify the problems that the disparate disciplines might have in common despite approaching them from different working principals (Wolff et al., 2017). The most common 
TABLE 1 | A comparison of the various properties of natural and synthetic materials.

\begin{tabular}{|c|c|c|c|c|c|c|c|c|c|c|c|c|c|}
\hline \multirow[b]{2}{*}{ Property } & \multicolumn{7}{|c|}{ Natural materials } & \multicolumn{6}{|c|}{ Synthetic materials } \\
\hline & $\begin{array}{l}\text { Spider } \\
\text { dragline } \\
\text { silk }\end{array}$ & $\begin{array}{c}\text { Silkworm } \\
\text { cocoon } \\
\text { silk }\end{array}$ & Wool & Resilin & Elastin & Byssus & Cotton & $\begin{array}{l}\text { Viscose } \\
\text { rayon }\end{array}$ & $\begin{array}{c}\text { Polyester } \\
\text { fiber } \\
\text { composite }\end{array}$ & $\begin{array}{l}\text { Nylon } \\
\text { fiber }\end{array}$ & $\begin{array}{l}\text { Synthetic } \\
\text { rubber }\end{array}$ & Kevlar & $\begin{array}{c}\text { Carbon } \\
\text { fiber }\end{array}$ \\
\hline $\begin{array}{l}\text { Strength } \\
(\mathrm{GPa})\end{array}$ & $0.2-1.6^{a}$ & $0.6^{b}$ & $0.2^{b}$ & $0.003^{b}$ & $0.002^{b}$ & $0.06-0.12^{c}$ & $0.4^{d}$ & $0.03^{e}$ & $0.02-0.07^{e}$ & $0.95^{\mathrm{b}}$ & $0.05^{b}$ & $3.6^{b}$ & $4^{b}$ \\
\hline $\begin{array}{l}\text { Toughness } \\
\left(\mathrm{MJ} \mathrm{m}^{-3}\right)\end{array}$ & $10-350^{a}$ & $70^{b}$ & $60^{b}$ & $4^{b}$ & $2^{b}$ & $20-40^{c}$ & $100-150^{d}$ & $4^{e}$ & $0.6-20^{e}$ & $80^{b}$ & $100^{\mathrm{b}}$ & $50^{b}$ & $25^{b}$ \\
\hline $\begin{array}{l}\text { Extensibility } \\
\left(\mathrm{mm} \mathrm{mm}^{-1}\right)\end{array}$ & $0.05-0.5^{a}$ & $0.1-0.3^{b}$ & $0.5^{\mathrm{b}}$ & $1.9^{b}$ & $1.5^{\mathrm{b}}$ & $0.7-1.0^{\mathrm{C}}$ & $0.55^{d}$ & $0.3^{\mathrm{e}}$ & $0.02-0.18^{f}$ & $0.18^{b}$ & $8.5^{b}$ & $0.027^{b}$ & $0.013^{b}$ \\
\hline $\begin{array}{l}\text { Stiffness/ } \\
\text { Elastic } \\
\text { modulus } \\
\text { (GPa) }\end{array}$ & $1-15^{a}$ & $7-15^{b}$ & $0.5^{b}$ & $0.002^{b}$ & $0.001^{b}$ & $0.13-0.4^{\mathrm{c}}$ & $2.0-3.7^{d}$ & $0.05^{e}$ & $0.1-3^{f}$ & $5^{b}$ & $0.001^{b}$ & $130^{b}$ & $300^{b}$ \\
\hline $\begin{array}{l}\text { Density } \\
\left(\mathrm{g} \mathrm{cm}^{3}\right)\end{array}$ & $1.3^{9}$ & $1.4^{\mathrm{h}}$ & $1.5^{\mathrm{i}}$ & $1.3^{j}$ & - & - & $1.54^{d}$ & $1.5^{f}$ & $1.1^{f}$ & $1.2^{f}$ & $0.9^{f}$ & $1.5^{f}$ & $2^{f}$ \\
\hline
\end{tabular}

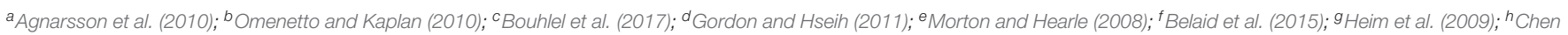
et al. (2012); 'Dmitrievich et al. (2014); ${ }^{j}$ Elvin et al. (2005).

difficulty in the instance of programs intending to produce spider silk-like fibers is producing fibers with the same mechanical performance as natural silk fibers, as developing large quantities of fibers of inferior performance is somewhat futile (Bini et al., 2006; Heidebrecht and Scheibel, 2013). Nevertheless, all fibers developed within the various laboratories have thus far not been of similar quality as naturally spun spider silks (Koh et al., 2015); even when complete or near complete gene or amino acid sequences had been replicated. There are obviously secretory, assembly and spinning functions that we do not fully understand and need to investigate further.

There are numerous studies documenting how dragline silk performance influences the evolutionary ecology of the spider that secretes it (e.g., Blamires et al., 2012a,b; Lacava et al., 2018; Viera et al., 2019). These studies show that spiders can tune the properties of their silks to accommodate different uses of the silk across different ecological circumstances. They thus provide a basis for bioprospecting for extremely high performing silks for biomimetics programs (Agnarsson et al., 2010), and might be used to pinpoint the most flexible mechanical properties of a particular silk to show us how to better control property variability (Blamires et al., 2017). Nonetheless, few studies have documented all of the relevant property variations across macroto nano scales (but see Blamires et al., 2018; Lacava et al., 2018). A deeper exploration of this largely untapped research space will enable the development of biomimetic protocols with more precise control of property variability.

The next common problem for the development of spider silk biomimetics programs is that of scaled production. Just as we eventually moved from large-scale harvesting and processing of natural fibers like cellulose to the production of synthetic fiber materials with exceptional strength like Rayon (regenerated cellulose) and Kevlar (polyaraphenylene terephthalamide) (see Morgan, 1981), a significant shift in paradigm is needed to move to large-scale manufacture of silk fibers. Biomimetic approaches hold promise for such a shift, as there are existing parallels between synthetic polymer fiber production and processes developed through evolutionary adaptations. For example, synthetic fibers are routinely produced by pumping highly viscous polymer melts through small spinneret openings. The polymer melts used for synthetic fibers have unique flow behavior that is also similar to spider silk precursors, as they are quite viscous when immobile but become more than 10 times thinner as they are pushed through the spinneret opening (Kojic et al., 2006; Porter and Vollrath, 2009). Another similarity between synthetic fiber and natural silk production is the shape of the entrance region in some natural and industrial spinnerets; both having a hyperbolic tapering that is advantageous for uniformity of flow (Lefèvre and Auger, 2016). Clearly the engineering of such processes will need to take advantage of the expertise gained from synthetic material processes, while closely studying natural processes and their properties.

From the design viewpoint, large amounts of fibers with desirable qualities built into them are needed to construct fibrous yarns on a commercially viable scale. Biological researchers thus must be able to produce large masses of extremely high quality spider silk fibers using existing recombinant or polymer engineering technologies (Bini et al., 2006; Xia et al., 2010; Heidebrecht and Scheibel, 2013; Jastrzebska et al., 2016; Blamires et al., 2017). We consider it imperative to set about identifying the obstacles to scaling through research that follows bottom-up and top-down approaches (exemplified by Figure 1 and discussions within Tarakanova and Buehler, 2012).

Studies of natural spider silk variability indicate that producing silk involves a complex relationship between competing ecological cost to the animal and silk performance (Craig et al., 2000; Wilder, 2011; Blamires et al., 2012a, 2015a,b). There is speculation among researchers as to what this cost(s) might be, including metabolic or nutritional stress (Craig et al., 2000; Guehrs et al., 2008; Blamires et al., 2012a), but there is no 
clear consensus. Identifying the cost(s) is nonetheless worthy of further investigation as undue costs can adversely affect the ability to significantly scale up production of biomimetic processes (Wolff et al., 2017).

The suppression of key nutrients and/or metabolic rates in spiders under dietary stress leads to a compromised investment in key amino acids and other building blocks of the silk proteins (Craig et al., 2000; Guehrs et al., 2008; Blamires et al., 2012a), leading to a compromise in properties (Zax et al., 2004; Blamires et al., 2015a, 2018). It thus seems like the investment costs are most prominent and identifiable when the spider is under dietary stress (Blamires et al., 2017). It also seems that metabolic and/or nutritional stresses are not the only factors limiting the quantity and quality of silks produced by spiders (Su and Buehler, 2016; Blamires et al., 2017). To uncover these other limitations cross-disciplinary research utilizing a "toolbox" methodology are required to systematically assess spider metabolism, nutrition, gene expression, silk structures, and mechanical properties.

Another problem we recognize here is our general incomplete or disjointed understanding of the underlying gene and/or amino acid sequences of most of the spidroins (the technical name for silk proteins). The consequence of this is that incomplete or partially complete sequences are often used in cloning and recombinant development programs, leading to the production of significantly smaller $(20-50 \mathrm{kDa}$ as opposed to $200+\mathrm{kDa}$ ) proteins that behave differently (Rammensee et al., 2008; Liu and Zhang, 2011; Heidebrecht and Scheibel, 2013). For instance, they coagulate at high concentrations and/or polymerize under different conditions than do full length protein sequences (Heim et al., 2009). The recent determination of full-length spider silk genomes (e.g., Garb et al., 2019; Kono et al., 2019) provides valuable information on the size and sequence of the various spidroins, as well as insights into the way they are secreted, stored, and spun in vivo. According to Carlson's Curve (Carlson, 2010) the ability to sequence and synthesize full genomes are becoming exponentially more cost effective over time. We are accordingly confident that the opportunity to develop and utilize full length spidroin sequences will be soon realized.

Even if the full gene sequences of the spidroins that we want cloned are known, producing spidroins en mass in up to $80 \%$ concentration (as in spider silk glands; Chaw et al., 2015), still presents an additional challenge. Recombinant technologies, i.e., the transferral of the silk genes to bacterial or yeast hosts to express the proteins, appears to be the cheapest and most reliable way to develop silk proteins (Torakeva et al., 2013). Attaining full length recombinant spider silk proteins is nevertheless still difficult because the length and size of the various spidroins render them difficult for bacterial hosts to synthesize and secrete, and for researchers to isolate and purify in solution (Heidebrecht and Scheibel, 2013; Wolff et al., 2017). The storage of the spidroins at high concentration facilitates the formation of micellar structures promoted by the alternating hydrophobic and hydrophilic regions across the protein terminal and core domains (Vollrath and Knight, 2001; Nova et al., 2010; Beun et al., 2014). Nevertheless, spidroins constructed in the lab using recombinant and other technologies tend to self-assemble and/or aggregate in high concentrations rather than forming micelles in solution (Hoffmann et al., 2018). Hence the storage capacity of laboratory synthesized spidroins is severely limited, which affects the shear stresses that the proteins experience within the spinning column, thereby hindering sol development, thus affecting the physical properties of the spun fibers (Heidebrecht and Scheibel, 2013; Wolff et al., 2017; Hoffmann et al., 2018). Nonetheless, when solubilized in high concentration under precise $\mathrm{pH}$ and ionic conditions, spidroins can form liquid crystallites (Vollrath and Knight, 2001). Knowledge of analogous processes, such as the natural bacterial production of nanocellulose fibers by Aceobacter xylinum (Iguchi et al., 2000) may accelerate the development of silk-like materials by similar means, as well as exemplifying processes to engineer the use of such materials (Song et al., 2019).

Finally, we contemplate whether it is possible to fully recreate all of the natural production processes associated within spider silk and, if not, which ones should biomimetic programs harness (Naik and Stone, 2005)? Evolution by natural selection modifies organismal processes over 1,000s of generations with the reproductive successes of the organism's progeny being the measure of its success. Spiders have evolved a toolkit of secretions that interact across scales; from gene expression to the formation of proteins, protein structures, fibers and, ultimately, webs and other extended phenotypes that perform specific biological functions (Blamires et al., 2017). Accounting for all of the physiological, biochemical, and ecological processes acting preand post-spinning to affect silk performance is nonetheless not easily replicable in the laboratory (Blamires et al., 2012b).

Biodesign is the use of organisms to enhance the function or production systems, where the border between mechanical and biological processes merge (Myers, 2014; Oxman, 2015). The challenge is to accommodate methodologies that combine topdown design procedures with bottom-up processes. Biodesigns have proven scalable and their applications are complementary with biological principles (Speck et al., 2017). Biodesign and biomimetic systems could then potentially be combined in a way to provide a wearables development framework based on spider silks and other high-performance natural materials. A key aspect of scalability of fiber manufacturing processes is an understanding of the parameters needed to produce specific product attributes and developing the models to link material properties to optimized manufacture. Such models exist for synthetic polymer spinning processes (Doufas et al., 2000) and can be re-applied to silk spinning using mechanical property characterization techniques specific to the stretching flows required for fiber production (Tripathi et al., 2000). Insights gained from such measurements will enable rapid feedback during material formation, process development, and scaled up biomanufacturing, as demonstrated by recent innovations (Boulet-Audet et al., 2019).

The objective of our prospective research is to develop new environmentally-friendly yet robust and light-weight wearable technologies from spider silk-like fibers that we develop by combining biomimetics research programs with a biodesign framework. This objective is ambitious, but we believe it is achievable utilizing the multidiscipline research toolbox approach. We thus provide some speculative examples 
about how current research projects in the Spider Silk Research Lab might proceed to the development of new wearable technologies.

Example 1: We recently found the dry cribellate capture silk of the Tasmanian cave spider, Hickmania troglodytes, to combine hydrophobic and hydrophilic properties that vary in a multitude of ways both as the spider ages and across habitats. We speculate that a closer examination of the biological mechanisms facilitating the hydrophobic-hydrophilic switching in this type of silk will make it possible to biomimetically engineer silk-like fibers woven into microencapsulated white graphene to provide an on-off switch for the incorporation in smart celluloses and other wearable fibers and fabrics.

Example 2: Our work on the optical properties of spider dragline silk has shown that the silk's textured surface and crystalline structures primarily influences its colouration (Blamires et al., 2019). Examining the surface features of the silk more closely might thus enable us to copy the fibers' surface

\section{REFERENCES}

Abascal, N. C., and Regan, L. (2018). The past, present and future of protein based materials. Open Biol. 8:180113. doi: 10.1098/rsob.180113

Agnarsson, I., Kuntner, M., and Blackledge, T. A. (2010). Bioprospecting finds the toughest biological material: extraordinary silk from a giant riverine orb spider. PLoS ONE 5:e11234. doi: 10.1371/journal.pone.0011234

Belaid, S., Chabira, S. F., Ballard, P., Sebaa, M., and Belhouide, S. (2015). Thermal aging effect on the mechanical properties of polyester fiberglass composites. J. Mater. Env. Sci. 6, 2795-2803.

Beun, L. H., Storm, I. N., Werten, M. W. T., de Wolf, F. A., Cohen Stuart, F. A., and de Vries, R. (2014). From micelles to fibers: balancing self-assembling and random coiling domains in $\mathrm{pH}$-responsive silk-collagen-like protein-based polymers. Biomacromolecules 15, 3349-3357. doi: 10.1021/bm500826y

Bini, E., Foo, C. W. P., Huang, J., Karageorgiou, V., Kitchel, B., and Kaplan, D. L. (2006). RGD-functionalized bioengineered spider dragline silk biomaterial. Biomacromolecules 7, 3139-3145. doi: 10.1021/bm0607877

Blamires, S. J., Blackledge, T. A., and Tso, I. M. (2017). Physicochemical property variation in spider silk: ecology, evolution, and synthetic production. Annu. Rev. Entomol. 62, 443-460. doi: 10.1146/annurev-ento-031616-035615

Blamires, S. J., Cerexhe, G., White, T. E., Herberstein, M. E., and Kasumovic, M. M. (2019). Spider silk colour covaries with thermal properties but not protein structure. J. Roy. Soc. Interf. 16:20190199. doi: 10.1098/rsif.2019.0199

Blamires, S. J., Liao, C. P., Chang, C. K., Chuang,Y. C., Wu, C. L., Blackledge, T. A., et al. (2015a). Mechanical performance of spider silk is robust to nutrientmediated changes in protein composition. Biomacromolecules 16, 1218-1225. doi: 10.1021/acs.biomac.5b00006

Blamires, S. J., Nobbs, M., Martens, P. J., Tso, I. M., Chuang, W. S., Chang, C. K., et al. (2018). Multiscale mechanisms of nutritionally induced property variation in spider silks. PLoS ONE 13:e0192005. doi: 10.1371/journal.pone.0192005

Blamires, S. J., Piorkowski, D., Chuang, A., Tseng, Y. H., Toft, S., and Tso, I. M. (2015b). Can differential nutrient extraction explain property variations in a predatory trap? Roy. Soc. Open Sci. 2:140479. doi: 10.1098/rsos.140479

Blamires, S. J., Wu, C. L., Blackledge, T. A., and Tso, I. M. (2012b). Environmentally induced post-spin property changes in spider silks: influences of web type, spidroin composition and ecology. Biol. J. Linn. Soc. 106, 580-588. doi: 10.1111/j.1095-8312.2012.01884.x

Blamires, S. J.,Wu, C. L., and Tso, I. M. (2012a). Variation in protein intake induces variation in spider silk expression. PLOS ONE 7:e31626. doi: 10.1371/journal.pone.0031626

Bouhlel, Z., Genard, B., Ibrahim, N., Carrington, E., Babarro, J. M. F., Lok, A., et al. (2017). Interspecies comparison of the mechanical properties textures to create chromogenic fabrics incorporating micro-scale weave structures and knots to create unique colourations without using dyes or pigments.

Example 3: We know that the flexibility and toughness of spider dragline silk are adaptive across a web or fiber, and can be tailored to suit a particular purpose. Accordingly, an engineered material that can replicate the selective flexibility of spider silk may be a useful "smart" material that can vary in property and compliance across environments. Since human skin needs to adapt its functionality across the human body, a deeper investigation of dragline silk's variability across environments might facilitate the development of more biocompatible synthetic skins, skin grafts, garments, patches, threads, biomembranes, or buttresses (Foo and Kaplan, 2002; Scheibel, 2004; Lee et al., 2007).

\section{AUTHOR CONTRIBUTIONS}

SB and PF conceptualized the manuscript, and all authors wrote and approved the manuscript. and biochemical composition of byssal threads. J. Exp. Biol. 220, 984-994. doi: $10.1242 /$ jeb.141440

Boulet-Audet, M., Rice, G. W., Moody, K. M., Bainbridge, J. M., Tom, S., Davijani, A. A. B., et al. (2019). Methods of Generating Recombinant Spider Silk Protein Fibers. Emeryville, CA: U.S. Patent Application 16/176,939, 1-55.

Browne, M. A., Dissanayake, A., Galloway, T. S., Lowe, D. M., and Thompson, R. C. (2008). Ingested microscopic plastic translocates to the circulatory system of the mussel, Mytilus edulis (L.). Env. Sci. Technol. 42, 5026-5031. doi: $10.1021 /$ es 800249 a

Carlson, R. (2010). Biology Is Technology: The Promise, Peril, and New Business of Engineering Life. Cambridge, MA: Harvard University Press. doi: $10.4159 / 9780674053625$

Carr, C., and Gibson, C. (2016). Geographies of making: rethinking materials and skills for volatile futures. Progr. Human Geogr. 40, 297-315. doi: 10.1177/0309132515578775

Chaw, R. C., Correa-Garhwal, S. M., Clarke, T. H., Ayoub, N. A., and Hayashi, C. Y. (2015). Proteomic evidence for components of spider silk synthesis from black widow silk glands and fibers. J. Proteom. Res. 14, 4223-4231. doi: 10.1021/acs.jproteome.5b00353

Chen, P. Y., McKittrick, J., and Meyers, M. A. (2012). Biological materials: functional adaptations and bioinspired designs. Prog. Mater. Sci. 57, 1492-1704. doi: 10.1016/j.pmatsci.2012.03.001

Craig, C. L., Riekel, C., Herberstein, M. E., Weber, R. S., Kaplan, D., and Pierce, N. E. (2000). Evidence for diet effects on the composition of silk proteins produced by spiders. Mol. Biol. Evol. 17, 1904-1913. doi: 10.1093/oxfordjournals.molbev.a026292

Damiati, S., Mhanna, R., Kodzius, R., and Ehmoser, E. K. (2018). Cellfree approaches in synthetic biology utilizing microfluidics. Genes 9:144. doi: 10.3390/genes9030144

De Falco, F., Gullo, M. P., Gentile, G., Di Pace, E., Cocca, M., Gelabert, L., et al. (2018). Evaluation of microplastic release caused by textile washing processes of synthetic fabrics. Env. Poll. 236, 916-925. doi: 10.1016/j.envpol.2017.10.057

Dmitrievich, Z. A., Viktorovna, S. T., Borisovich, Z. D., and Olegovna, K. A. (2014), Thermal treatment of the mineral wool mat. Adv. Mater. Res. 838, 196-200. doi: 10.4028/www.scientific.net/AMR.838-841.196

Doufas, A. K., McHugh, A. J., and Miller, C. (2000). Simulation of melt spinning including flow-induced crystallization: part I. Model development and predictions. J. Non-Newt. Fluid Mech. 92, 27-66. doi: 10.1016/S0377-0257(00)00088-4

Eadie, L., and Ghosh, T. K. (2011). Biomimicry in textiles: past, present and potential. An overview. J. Roy. Soc. Interf. 8, 761-775. doi: $10.1098 /$ rsif.2010.0487 
Elvin, M. E., Carr, A. G., Huson, M. G., Maxwell, J. M., Pearson, R. D., Vuocolo, T., et al. (2005). Synthesis and properties of crosslinked recombinant pro-resilin. Nature 437, 999-1002. doi: 10.1038/nature04085

Flanagan, P. J. (2014). "A vibrant evolution: from wearable devices to objects as mediators of experience," in Design, User Experience and Usability: User Experience Design for Everyday Life Applications and Services, ed A. Marcus (Cham, SZ: Springer), 675-686. doi: 10.1007/978-3-319-07635-5_64

Foo, C. W. P., and Kaplan, D. L. (2002). Genetic engineering of fibrous proteins: spider dragline silk and collagen. Adv. Drug Deliv. Rev. 54, 1131-1143. doi: 10.1016/S0169-409X(02)00061-3

Franklin, K. (2018). Radical Matter: Rethinking Materials for a Sustainable Future. London: Thames \& Hudson.

Garb, J. E., Haney, R. A., Schwager, E. E., Gregoric, M., Kuntner, M., Agnarsson, I., et al. (2019). The transcriptome of Darwin's bark spider silk glands predicts proteins contributing to dragline silk toughness. Comm. Biol. 2:275. doi: 10.1038/s42003-019-0496-1

Gellynck, K., Verdonk, P., Forsyth, R., Almqvist, K. F., Van Nimmen, E., Gheysens, T., et al. (2008). Biocompatibility and biodegradability of spider egg sac silk. J. Mat. Sci. 19, 2963-2970. doi: 10.1007/s10856-007-3330-0

Gordon, S., and Hseih, Y. L. (2011). Cotton: Science and Technology. Boca Raton: CRC Press.

Guehrs, K. H., Schlott, B., Grosse, F., and Weisshart, K. (2008). Environmental conditions impinge on dragline silk protein composition. Ins. Mol. Biol. 17, 553-564. doi: 10.1111/j.1365-2583.2008.00826.x

Heidebrecht, A., and Scheibel, T. R. (2013). Recombinant production of spider silk proteins. Adv. Appl. Microbiol. 82, 115-152. doi: 10.1016/B978-0-12-407679-2.00004-1

Heim, M., Keerl, D., and Scheibel, T. R. (2009). Spider silk: from soluble protein to extraordinary fiber. Ang. Chem. Int. Ed. 48, 3584-3596. doi: 10.1002/anie.200803341

Hoffmann, B., Gruat-Henry, C., Mulitini, P., Jiang, L., Brooks, B. D., and Brooks, A. E. (2018). Using hydrodynamic focusing to predictably alter the diameter of synthetic silk fibers. PLoS ONE 13:e0195522. doi: 10.1371/journal.pone.0195522

Hwang, J., Jeong, Y., Park, J. M., Hong, J. W., and Choi, J. (2015). Biomimetics: forecasting the future of science, engineering, and medicine. Inter. J. Nanomed. 10, 5701-5713. doi: 10.2147/IJN.S83642

Iguchi, M., Yamanaka, S., and Budhiono, A. (2000). Bacterial cellulose-a masterpiece of nature's arts. J. Mater. Sci. 35, 261-270. doi: 10.1023/A:1004775229149

Jastrzebska, K., Felcyn, E., Kozak, M., Szybowicz, M., Buchwald, T., Pietralik, Z., et al. (2016). The method of purifying bioengineered spider silk determines the silk sphere properties. Sci. Rep. 6:28106. doi: 10.1038/srep28106

Koh, L. D., Cheng, Y., Teng, C. P., Khin, Y. W., Lo, X. J., Tee, S. Y., et al. (2015). Structures, mechanical properties and applications of silk fibroin materials. Prog. Polym. Sci. 46, 86-110. doi: 10.1016/j.progpolymsci.2015.02.001

Kojic, N., Bico, J., Clasen, C., and McKinley, G. H. (2006). Ex vivo rheology of spider silk. J. Exp. Biol. 209, 4355-4362. doi: 10.1242/jeb.02516

Kono, N., Nakamura, H., Ohtoshi, R., Pedrazzoli Moran, D. A., Shinohara, A., Yoshida, Y., et al. (2019). Orb-weaving spider Araneus ventricosus genome elucidates the spidroin gene catalogue. Sci. Rep. 9:8380. doi: 10.1038/s41598-019-44775-2

Lacava, M., Camargo, A., Garcia, L. F., Benamu, M., Santana, M., and Fang, J., et al. (2018). Web building and silk properties functionally covary among species of wolf spider. J. Evol. Biol. 31, 968-978. doi: 10.1111/jeb.13278

Lapidot, S., Meirovitch, S., Sharon, S., Heyman, A., Kaplan, D. L., and Shoseyov, O. (2012). Clues for biomimetics from natural composite materials. Nanomedicine 7, 1409-1423. doi: 10.2217/nnm.12.107

Le Quéré, C., Raupach, M. R., Canadell, J. G., Marland, G., Bopp, L., Ciais, P., et al. (2009). Trends in the sources and sinks of carbon dioxide. Nature Geosci. 2, 831-836. doi: 10.1038/ngeo689

Lee, K. S., Kim, B. Y., Je, Y. H., Woo, S. D., Sohn, H. D., and Jin, B. R. (2007). Molecular cloning and expression of the C-terminus of spider flagelliform silk protein from Araneus ventricosus. J. Biosci. 32, 705-712 doi: 10.1007/s12038-007-0070-8

Lefèvre, T., and Auger, M. (2016). Spider silk inspired materials and sustainability: perspective. Mater. Technol. 31, 384-399. doi: $10.1179 / 1753555715 Y .0000000065$
Liu, X., and Zhang, K. Q. (2011). "Silk fiber - molecular formation mechanism, structure- property relationship and advanced applications," in Oligomerization of Chemical and Biological Compounds, ed. C. Lesieur (Rejika, Croatia: In Tech), 69-101.

Morgan, P. W. (1981). Brief history of fibers from synthetic polymers. J. Macromol. Sci. 15, 1113-1131. doi: 10.1080/00222338108066456

Morton, W. E., and Hearle, J. W. S. (2008). Physical Properties of Textile Fibres, 4th Edn. Cambridge, UK: Woodhead. doi: 10.1533/9781845694425

Myers, W. (2014). Biodesign: Nature, Science, Creativity. London: Thames and Hudson.

Naik, R. R., and Stone, M. O. (2005). Integrating biomimetics. Mater. Today 8, 18-26. doi: 10.1016/S1369-7021(05)71077-4

Nguyen-Robertson, C. V., and Byrne, N. (2019). Circular Fashion: Turning Old Clothes Into Everything From New Cotton to Fake Knees. Melbourne, VIC: The Conversation.

Nova, A., Keten, S., Pugno, N. M., Redaelli, A., and Buehler, M. J. (2010). Molecular and nanostructural mechanisms of deformation, strength and toughness of spider silk fibrils. Nano Lett. 10, 2626-2634. doi: 10.1021/nl101341w

Omenetto, F. G., and Kaplan, D. L. (2010). New opportunities for an ancient material. Science 329, 528-531. doi: 10.1126/science.1188936

Oxman, N. (2015). Templating design for biology and biology for design. Archit. Design 85, 100-107. doi: 10.1002/ad.1961

Pawlyn, M. (2011). Biomimicry in Architecture. London: RIBA Publishing.

Porter, D., and Vollrath, F. (2009). Silk as a biomimetic ideal for structural polymers. Adv. Mater. 21, 487-492. doi: 10.1002/adma.200801332

Quinn, B. (2010). Textile Futures: Fashion, Design and Technology. Berg: Oxford NY.

Rammensee, S., Slotta, U., Scheibel, T. R., and Bausch, A. R. (2008). Assembly mechanism of recombinant spider silk proteins. Proc. Nat. Acad. Sci. U.S.A. 105, 6590-6595. doi: 10.1073/pnas.0709246105

Sanchez, C., Arribath, H., and Guille, M. M. (2005). Biomimetism and bioinspiration as tools for the design of innovative materials and systems. Nat. Mater. 4, 277-288. doi: 10.1038/nmat1339

Scheibel, T. R. (2004). Spider silks: recombinant synthesis, assembly, spinning, and engineering of synthetic proteins. Microbial Cell Fact. 3:14. doi: 10.1186/1475-2859-3-14

Song, J., Babayekhorasani, F., and Spicer, P. T. (2019). Soft bacterial cellulose microcapsules with adaptable shapes. Biomacromolecules 20, 4437-4446. doi: 10.1021/acs.biomac.9b01143

Speck, O., Speck, D., Horn, R., Gantner, J., and Sedlbauer, K. P. (2017). Biomimetic bio-inspired biomorph sustainable? An attempt to classify and clarify biology-derived technical developments. Bioinspir. Biomim. 12:011004. doi: 10.1088/1748-3190/12/1/011004

Su, I., and Buehler, M. J. (2016). Nanomechanics of silk: the fundamentals of a strong, tough and versatile material. Nanotechnology 27:302001. doi: 10.1088/0957-4484/27/30/302001

Szostak-Kotowa, J. (2004). Biodeterioration of textiles. Int. Biodeter. Biodegrad. 53, 165-170. doi: 10.1016/S0964-8305(03)00090-8

Tarakanova, A., and Buehler, M. J. (2012). The role of capture spiral silk properties in the diversification of orb webs. J. Roy. Soc. Interf. 9, 3240-3248. doi: 10.1098/rsif.2012.0473

Torakeva, O., Michalczechen-Lacerda, V. A., Rech, E. L., and Kaplan, D. L. (2013). Recombinant DNA production of spider silk proteins. Microb. Biotech. 6, 651-663. doi: 10.1111/1751-7915.12081

Tripathi, A., Whittingstall, P., and McKinley, G. H. (2000). Using filament stretching rheometry to predict strand formation and "processability" in adhesives and other non-Newtonian fluids. Rheol. Acta 39, 321-337. doi: $10.1007 / \mathrm{s} 003970000072$

Viera, C., Garcia, L. F., Lacava, M., Fang, J., Wang, X., Kasumovic, M. M., et al. (2019). Silk physico-chemical variability and mechanical robustness facilitates intercontinental invasibility of a spider. Sci. Rep. 9:13273. doi: 10.1038/s41598-019-49463-9

Vollrath, F., and Knight, D. P. (2001). Liquid crystalline spinning of spider silk. Nature 410, 541-548. doi: 10.1038/35069000

Waite, J. H. (1992). "The formation of mussel byssus: anatamoy of a natural manufacturing processes," in Structure, Cellular Synthesis and Assembly of Biopolymers, ed S. T. Case (Berlin: Springer-Verlag), 27-54. doi: 10.1007/978-3-540-47207-0_2 
Wegst, U. G., Bai, H., Saize, E., Tomsia, A., and Ritchie, R. O. (2015). Bioinspired structural materials. Nat. Mater. 14, 23-36. doi: 10.1038/nmat4089

Wilder, S. M. (2011). Spider nutrition: an integrative perspective. Adv. Ins. Physiol. 40, 87-136. doi: 10.1016/B978-0-12-387668-3.00002-7

Wolff, J. O., Wells, D., Reid, C. R., and Blamires, S. J. (2017). Clarity of objectives and working principles enhances the success of biomimetic programs. Bioinspir. Biomim. 12:051001. doi: 10.1088/1748-3190/aa86ff

Wu, Y., Shah, D. U., Liu, C., Yu, Z., Ren, X., Rowland, M. J., et al. (2017). Bioinspired supramolecular fibers drawn from a multiphase self-assembled hydrogel. Proc. Nat. Acad. Sci. U.S.A. 114, 8163-8168. doi: 10.1073/pnas.1705380114

Xia, X. X., Qian, Z. G., Ki, C. S., Park, Y. H., Kaplan, D. L., and Lee, S. Y. (2010). Native-sized recombinant spider silk protein produced in metabolically engineered Escherichia coli results in a strong fiber. Proc. Nat. Acad. Sci. U.S.A. 107, 14059-14063. doi: 10.1073/pnas.1003366107
Zax, D. B., Armanios, D. E., Horak, S., Malowniak, C., and Yang, Z. (2004). Varaition of mechanical properties with amino acid content in the silk of Nephila clavipes. Biomacromolecules 5, 732-738. doi: 10.1021/bm034309x

Conflict of Interest: The authors declare that the research was conducted in the absence of any commercial or financial relationships that could be construed as a potential conflict of interest.

Copyright (c) 2020 Blamires, Spicer and Flanagan. This is an open-access article distributed under the terms of the Creative Commons Attribution License (CC BY). The use, distribution or reproduction in other forums is permitted, provided the original author(s) and the copyright owner(s) are credited and that the original publication in this journal is cited, in accordance with accepted academic practice. No use, distribution or reproduction is permitted which does not comply with these terms. 